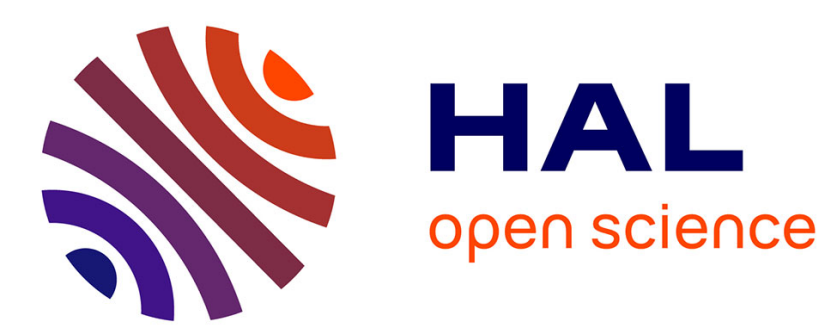

\title{
Comparative Study of the Mobile Learning Architectures
}

Sameh Baccari, Florence Mendes, Christophe Nicolle, Fayrouz Soualah-Alila, Neji Mahmoud

\section{- To cite this version:}

Sameh Baccari, Florence Mendes, Christophe Nicolle, Fayrouz Soualah-Alila, Neji Mahmoud. Comparative Study of the Mobile Learning Architectures. e-LEOT 2nd EAI International Conference on e-Learning e-Education and Online Training, Sep 2015, Novedrate, Italy. hal-01238370

\section{HAL Id: hal-01238370 \\ https://hal.science/hal-01238370}

Submitted on 8 Dec 2015

HAL is a multi-disciplinary open access archive for the deposit and dissemination of scientific research documents, whether they are published or not. The documents may come from teaching and research institutions in France or abroad, or from public or private research centers.
L'archive ouverte pluridisciplinaire HAL, est destinée au dépôt et à la diffusion de documents scientifiques de niveau recherche, publiés ou non, émanant des établissements d'enseignement et de recherche français ou étrangers, des laboratoires publics ou privés. 


\title{
Comparative study of the mobile learning architectures
}

\author{
Sameh Baccari **, Florence Mendes+, \\ Christophe Nicolle+, Fayrouz Soualah-Alila+, and Mahmoud Neji ** \\ **MIRACL, Université of Sfax, Tunisie \\ sameh baccari@yahoo.fr, Mahmoud.neji@fsegs.rnu.tn \\ + LĒ2I, UMR CNRS 6306, Université of Bourgogne, Dijon, France \\ \{fayrouz.soualah-alila, florence.mendes\} @checksem.fr, \\ cnicolle@u-bourgogne.fr
}

\begin{abstract}
With the emergence of mobile devices (Smart Phone, PDA, UMPC, game consoles, etc.), learning is changing from electronic learning (e-Learning) to mobile learning (m-learning). In fact, due to the mobility feature, it seems that the m-learning have to be adapted with the change within the context. Several researches addressed this issue and implemented a mobile learning environment to prove its usefulness and feasibility in various domains. In this article, we conduct a comparative study between a list of mobile learning architectures and methods that are presented in the literature. The performance of these architectures is evaluated based on several criteria, such as the adaptation management, which is an important parameter for the management and customization of the learning resources for the learners, as well as the environment, which is a core part of mobile learning systems.
\end{abstract}

Keywords: Mobile Technology; M-learning; Context; Adaptation; Learning method

\section{Introduction}

Mobile learning has become an important issue for educators and computer scientists. Thanks to large number of practical suggestions, the learner can continue his education using a mobile device whether a Smartphone or a tablet. M-learning objects can take many forms such as text, audio or video documents organized into comprehensive training programs adapted to mobile devices. While, there are a large number of courses available on mobile devices, this type of training is still at an early stage. The adaptation of the mobile devices with the available contents in e-Learning is sometimes difficult. In fact, the problems to migrate e-learning training course to mobile learning systems are not only limited to technical issue such as: the limitation of screen size and the band with. The management of change within the context and its impact on the training course remains a problem. In addition, even if, some contents, such as audio and video media course materials, are ideally suitable for mobile use, the existing systems are still unsatisfactory for the users' needs. Our goal is to check existing mobile-learning methods in order to identify how they resolve the technical heterogeneity and bridge the gap change management during the mobile learning process. 
The remainder of this article is organized as follows. In Section 2, we give a brief definition of the mobile learning. Then, the context and the opportunities of contextaware applications are described in more detail in Section 3. Then, in Section 4, a list of some existing works in the literature is presented. Then a comparison between the different architectures presented in these works is established using a list of significant criteria. Finally, in Section 6, a conclusion is drawn.

\section{Mobile learning}

M-learning is described by the use of mobile and wireless technologies allowing anyone to access information and learning materials regardless of the place and at any time. Some approaches consider that mobile learning is simply an extension of the Elearning. However, these approaches do not take into account the limitations of the mobile device and the particular circumstances of mobile learning and the added value of mobility such as learning on demand, in context, through contexts, informal, etc. Mobile learning has been defined as: the process of learning and teaching that occurs with the use of mobile devices providing flexible on-demand access (without time and device constraints) to educational resources, experts, peers and services from any place [1].

This evolution of learning can be characterized by the following changes: the introduction of distance in e-learning, and the taking account of mobility with mlearning and omnipresence with the ubiquity ubiquitous learning (ubiquitous learning, pervasive learning). These steps reflect the impact of computer technology, such as mobile and ubiquitous computing.

The shift from e-learning to mobile learning has given rise to much debate among researchers. An example, Sharma noticed that the shift from e-learning to mobile learning is accompanied by a change in the terminology [2]: shown in Table 1.

Table 1.Comparison of e-learning terminology and mobile learning (according to [3])

\begin{tabular}{ll}
\hline \multicolumn{1}{c}{ E-learning } & \multicolumn{1}{c}{ M-learning } \\
\hline Computer & Mobile \\
Bandwidth & GPRS, 3G, Bluetooth \\
Multimedia & Objects \\
Interactive & Spontaneous \\
Hyperlinked & Connected \\
Distance learning & Situated learning \\
More formal & Informal \\
Simulated situation & Realistic situation \\
Hyper learning & Constructivism, situationism, collaborative \\
In classroom or internet labs & In the field or while mobile \\
\hline
\end{tabular}

The main benefits of mobile learning for education and learning are reported as follows [4]: (a) enables on-demand access to learning resources and services, as well as instant delivery of notifications and reminders, (b) offers new opportunities for learning that extend beyond the traditional teacher-led classroom-based activities, (c) encourage learners to participate more actively in the learning process by engaging them to authentic and situated learning embedded in real-life context and (d) supports 
on-demand access, communication and exchange of knowledge with experts, peers and communities of practice.

One big difference between learning somewhere on a stationary desktop computer and learning with mobile devices is the context, the user is in. Mobile devices feature some functionality to capture some background information that can be helpful to personalize the learning experience. When considering mobility from the learner's point of view, rather than the technology's, it is more important to say that m-learning is about people moving through environments, learning as they go, using electronic devices that enables connectivity to information sources and communication while they are able to change their physical location. In short, our new definition of mobile learning is "context-aware learning". The context- aware concept is discussed in some detail in the next sections.

\section{Mobile learning in context}

In a mobile learning experience, each learner has to be treated in a different way according to the current situation in which he is learning, e.g. according to his preknowledge or the specifications of the device, he is using. Those different conditions are called the context in which the learner is situated.

The term "context-aware" was brought and defined by Schilit et al. [5] to describe the location, identities of nearby people, objects and changes to the objects. Currently such terminology is used in various research disciplines; linguists provide two meanings for it. Context can be defined as the text in which a word or a passage appears and which helps to ascertain its meaning.

A very popular definition is given by Dey [6] who define context as "... any information that can be used to characterize the situation of an entity. An entity is a person, place, or object that is considered relevant to the interaction between the user and the application, including the user and the applications themselves." In mlearning, the context has been proposed to be modelled into two parts: one related to the learning design and another related to the mobile environment in which learners interact by completing learning activities [7]. These two categories are referred to as learning context and mobile context [8].

Learning context can be described by the elements of a learning design. A learning design is defined as:

" the description of the teaching-learning process, which follows a specific pedagogical modelor practice that takes place in a unit of learning (e.g., a course, a learning activity or any other designed learning event) towards addressing specific learning objectives, for a specific target group in a specific context or subject domain"[9].

Mobile context can be referred to as contextual information such as people, technological artifacts, learner's location and its physical conditions, available time, etc., which can be captured by hardware, measured by sensors or even entered by the learner. We are considering a classification of the mobile context characteristics with eight dimensions based on characteristics defined by mobile context-related research works [10].

Harnessing context in a mobile learning experience has a wide range of benefits including personalization, adaptation, intelligent feedback, and recommendation. 
Adding context information to an application may lead to presenting more personalized data to the learner. If there is no context information available, every learner has to be treated the same way. Context may contain information about the current situation, in which the learner is in, her pace, knowledge, interest, peers, motivation, etc. This knowledge enables applications to present only those parts of the learning activity that are of interest in that special situation [11]. Context-aware mobile learning systems can adapt to every situation, give intelligent feedback to the preceding learning process, and produce recommendations for new learning items or activities.

Subsequently, the focus will be on the studies which implemented a mobile learning environment to prove their usefulness and feasibility in different domains.

\section{Previous works}

In this section, we will review the work existing in the literature by presenting representative approaches and platforms of mobile learning. The interest is in the adaptation management, which is a very important parameter in managing and customizing the learning resources to the learners. The focus will also be on the context, which is a central core of all the mobile learning systems.

MOBILearn is a European research and development project which aims at exploring the use of mobile environments to foster informal learning, learning through problem solving and learning at work. As part of this project, a new architecture for mobile learning was constructed. It can help generate contents and services to accompany a learner during his learning activities in a gallery or a museum [12]. Learning is backed by a set of activities at the museums. Being placed in front of a painting, the visitors can then use a PDA or Smartphone to get the relevant information while observing the painting in order to learn. A learner visiting a museum for the second time can acquire information related to his previous visit.

eBag is part of the iSchool project for nomadic and mobile learning [13] for which mobility and context are two key elements. In short, the iSchool project vision is to develop a software infrastructure, graphical interfaces and spatial concepts in an interactive environment. The idea behind eBag is the creation of a "virtual schoolbag" for each student to help him learn through contexts by moving to specific locations (classrooms, laboratories, workshops, libraries, museums, cities, clubs and at home). The objective of the system is therefore to serve as a "personal and digital warehouse" in which all the resources (texts, photos, videos, etc.) can be stored for internal and external use of the school environment.

The MoULe project (Mobile and Ubiquitous Learning) aims to suggest that the pupils use mobile devices to build up collaborative knowledge. It also aims at the use of mobile devices incorporating learning activities in the classroom and laboratory for situation learning. The MoULe is an environment that helps the users edit and share documents and concept maps using desktop computers and smart phones equipped with GPS. The latter ones enable students to collect textual content, images, videos and audio recordings while visiting an outside site during their learning activities. The system also helps them comment on the media they collect to classify it so that their research and the re-use of the information in collaborative activities will be easy [14]. 
The CoMoLE project is a platform called adaptive based on Context-Mobile Learning Environments. The users can access the environments supported by CoMoLE different devices via a Web browser. CoMoLE supports the recommendation and the fulfillment of various types of learning activities, such as reading comprehensions, observing examples, doing tests and short unanswered exercises, solving problems together, downloading e-materials for their study, sending/receiving messages to/from partners of the same workgroup, and so on. The activities may have associated multimedia content and collaboration tools to support the interaction between the members of the same group in the case of collaborative activities. Each activity can be devoted to everyone, to certain types of users, or only to users in specific contexts. These coping capacities are defined by rules [15].

Nguyen Pham and Ho present CAMLES (Context-Aware m-Learning System) to help students learn English as a foreign language to prepare them for TOEFL test by suggesting topics that they need to learn on the basis of their test results. The test provides an adaptive content for different learners in context, including location, time and the learner's knowledge [16].

Chuantao YIN proposed the design for a contextual mobile learning system known as SAMCCO (French abbreviation for "contextual and collaborative mobile learning system for professional fields") [17]. This system is based on EPSS (Electronic Performance Support System), the goal of which is to group storage of technical, working and learning data in order to provide just-in-time, just enough training, information, tools and help for mastering or repairing equipment, appliances or products disseminated in the smart city environment. This system is able to provide appropriate information designed to maintain or ensure appropriate performance of smart city users when and where needed, thereby also enhancing the performance of the company as a whole and industry. EPSS is used to store and deliver plant reference materials including: training documents, operating procedures and historical maintenance information. SAMCCO edits and organizes learning contents stored in the EPSS information database, which is an essential professional learning resource offering abundant and well-structured learning contents.

In 2013, Soualah et al [18] proposed approach for context-based adaptation for m-earning, making use of learning practices already deployed in e-learning systems and adopting them in m-learning. This system is built around an ontology that both defines the learning domain and supports context-awareness. The use of this ontology facilitates context acquisition and enables a standard-based learning object metadata annotation. They also use a set of ontological rules to achieve personalized contextaware LOs by exploiting knowledge embedded in the ontology. The future adaptive system will offer an optimized panel of LOs matching with the current context of the learner.

The UoLmP project (Units of Learning Mobile Player) Project [20] is intended to present an adaptive and personalized mobile learning system, context sensitive, which aims to support the semi-automatic adaptation of the learning activities. This is about: (a) the accommodations to the interconnection of the learning activities (i.e. the learning flow) and (b) to the educational resources, tools and services that support the learning activities. The initial results of the assessment of the UoLmP use provide evidence that UoLmP can successfully be adapted to the learning flow of a pedagogical scenario and the provision of educational resources, tools and services 
that support the learning activities. Finally, these accommodations can help students successfully complete the learning activities of a pedagogical scenario.

Some of them will then be analyzed in the mobile learning systems that have been performed to show the features of the mobile learning mentioned in the previous section.

\section{Analyses and Discussion}

In this section we give a comparative study of the different approaches and architectures of mobile learning that we have presented in the previous section. This comparison is based on some significant criteria and features, we are particularly interested in device mobile support, heterogeneity support, reduce the bandwidth use, adaptability, traceability and control, learning is seen as activities in context, learning context-Aware, learning as a collaborative process, the integration of formal and informal learning, mobile learning - part of a whole. The result of this comparison is presented in table 2.The analysis of the existing studies has given us an overview of the opportunities provided by the mobile learning environments based on the individual needs. In fact, most of these studies enable learning in different locations (in the classroom, outdoors, in a museum, in companies, etc.).

Table 2.Comparative Study architectures of mobile learning

\begin{tabular}{|r|cccccccc|}
\hline Architecture & 1 & 2 & 3 & 4 & 5 & 6 & 7 & 8 \\
\hline Mobility support & $\checkmark$ & $\checkmark$ & $\checkmark$ & $\checkmark$ & $\checkmark$ & $\checkmark$ & $\checkmark$ & $\checkmark$ \\
Heterogeneity support & $\checkmark$ & - & $\checkmark$ & $\checkmark$ & - & - & $\checkmark$ & $\checkmark$ \\
Wireless communication technology & $\checkmark$ & $\checkmark$ & $\checkmark$ & $\checkmark$ & $\checkmark$ & $\checkmark$ & $\checkmark$ & $\checkmark$ \\
Formal and Informal learning & $\checkmark$ & $\checkmark$ & - & - & - & $\checkmark$ & $\checkmark$ & $\checkmark$ \\
Mobile learning - part of a whole & - & - & - & - & - & - & - & $\checkmark$ \\
Learning seen as a collaborative process & - & - & - & - & $\checkmark$ & - & - & - \\
Learning seen as a activities in context & - & - & - & - & $\checkmark$ & - & $\checkmark$ & - \\
Learning context-aware & $\checkmark$ & - & - & $\checkmark$ & - & $\checkmark$ & $\checkmark$ & $\checkmark$ \\
Adaptability & - & - & - & $\checkmark$ & - & - & $\checkmark$ & $\checkmark$ \\
Traceability and control & - & - & - & - & - & $\checkmark$ & - & - \\
\hline
\end{tabular}

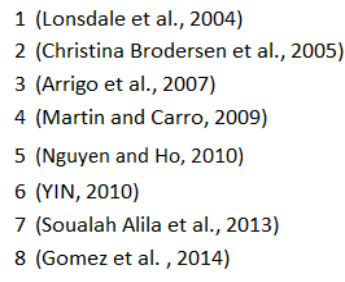

The most important feature that characterizes the works presented in soualah et al, SAMCCO and UoLmP projects is the Mobile learning in context. In fact, UoLmP can successfully be adapted to the learning flow of a lesson plan and to the provision of educational resources, tools and services that support the learning activities. SAMCCO is based on AM-LOM metadata and ontology, which are used in the learning unit model to describe and identify contextual mobile learning contents particularly in the professional field. Among the projects that are interested in the collaborative learning, we find CAMLES project. This project has considered the role of participants and the pedagogical purposes (collaborative missions) and supports. However, the MoULe project has helped teachers to organize scenarios in a limited way.

We have remarked that most approaches do not enable the adaptation between the course content and the learner's profiles. Context-aware approaches have the 
advantage of providing the user the appropriate learning resources depending on the context. It is therefore essential to determine, depending on the context, how, when, and on which interface the resources should be sent. However, Learning Through contextualization is not easy to achieve. In fact, the development of mobile technologies and the dynamics in the mobile environments have complicated the process of contextualization.

Today, mobile computing (user mobility, terminal mobility, and network mobility) is characterized by a permanent change in context (connected or disconnected, low or high bandwidth, change of location, widescreen or small screen, varying input devices, etc). Thus, it has become very complex, to consider many and various aspects when designing such application.

Mobile learning is very important particularly in education, and the major utilization of mobile devices is in the field of medicine. In fact, medical students are placed in hospital/clinical require in their training an access to course information while on the move. In addition, the work of the postgraduates and the physicians involves a high degree of mobility between distributed sites and instant communications within work environments. Distributed sites where physicians are working and in which students are placed are often in remote and rural areas. The technological advances can be capitalized to promote and facilitate situated learning. In fact, face the considerable growth of data, the heterogeneity of roles and needs and the rapid development of mobile systems, it becomes important to provide a system able to provide the user with a pertinent training adapted to their needs. This system requires a context-aware architecture, with mechanisms the change within the context. This architecture must take into account the different characteristics of the user as well as all of the contextual situations that influence their behavior when interacting with the mobile learning system.

\section{Conclusions}

In this article, we presented and compared the list of architectures of mobile learning according to a list of features. All the presented architectures are not able to detect the mobile learning environment or to get information about it. Therefore, they cannot be adapted. Our work is an extension of one of the presented m-learning approaches in which we propose the context management, the adaptation and the learning without a break through contexts. Our goal is to design a mobile learning architecture that supports the features of mobility and context in order to enhance the learning experience in the field of education, specifically in medical field.

\section{References}

1. Sharples, M., Roschelle, J., (2010). Guest editorial: special issue on mobile and ubiquitous technologies for learning. IEEE Transactions on Learning Technologies 3 (1), 4-5.

2. Sharma S. K. and Kitchens F. L. Web Services Architecture for M-Learning. Electronic Journal on eLearning. 2004; 2(1):203-216 
3. Laouris Y. We Need an Educationally Relevant Definition of Mobile Learning. 4th World conference on mLearning.MLearn2005, Cape Town, South Africa; 2005.

4. Lam, J., Yau, J., Cheung, S., (2010). A review of mobile learning in the mobile age. In: Proc. 3rd International Conference on Hybrid Learning, Lecture Notes in Computer Science Springer, Berlin, vol. 6248, pp. 306-315.

5. Schilit, B., Adams, N. and Want, R. (1994), Context-aware computing applications, in 'Mobile Computing Systems and Applications, 1994. WMCSA 1994.First Workshop on', pp. 85 -90.

6. Dey, A. (2001), 'Understanding and using context', Personal and ubiquitous computing 5(1), 4-7.

7. Pachler, N. Bachmair, B. and Cook, J. 2010. Mobile learning: Structures, agency, practices. New York, Springer

8. Siadaty, M. Torniai, C. Gašević, D. Jovanovic, J. Eap, T. and Hatala, M. 2008. mLOCO: An Ontology-based Framework for Context-Aware Mobile Learning, Sixth International Workshop on Ontologies and Semantic Web for E-Learning. Montreal, Canada 23-27 June

9. Koper, R. and Olivier, B. 2004. „Representing the Learning Design of Units of Learningee, Educational Technology \& Society, 7 (3), pp. 97-111

10. Kukulska-Hulme, A. 2009. „Practitioners as Innovators: Emergent Practice in Personal Mobile Teaching, Learning, Work, and Leisure ee, in Ally, M. (ed.) Mobile Learning: Transforming the Delivery of Education and Training. Edmonton: Athabasca University Press, pp. 135- 155

11. Hendrik Thüs, Mohamed Amine Chatti, Esra Yalcin, Christoph Pallasch, Bogdan Kyryliuk, Togrul Mageramov, and Ulrik Schroeder. Mobile Learning in Context

12. Lonsdale, P., \& Beale, R. (2004). Towards a dynamic process model of context.To appear in Proceedings of Ubicomp 2004 workshop on Advanced Context Modeling, Reasoning and Manage.

13. Brodersen, C., Christensen, B. G., Gronboek, K., Dindler, C., \& Sundararajah, B. (2005).eBag: a ubiquitous Web infrastructure for nomadic learning. Paper presented at the Proceedings of the 14th international conference on World Wide Web.

14. Arrigo, M., Giuseppe, O. D., Fulantelli, G., Gentile, M., Novara, G., Seta, L., et al. (2007). A Collaborative M-Learning Environment. Paper presented at the 6th Annual International Conference on Mobile Learning, mLearn 2007, Melbourne Australia, 13-22.

15. Martin, E., Carro, R.M., (2009). Supporting the development of mobile adaptive learning environments: a case study. IEEE Transactions on Learning Technologies 2 (1), 23-36. http://dx.doi.org/10.1109/ TLT.2008.24

16. Nguyen V.A. Pham, Ho S.D (2010). A Context - Aware Mobile Learning Adaptive System for Supporting Foreigner Learning English". International Conference on Computing and Communication Technologies, Research, Innovation, and Vision for the Future (RIVF), 2010 IEEE RIVF,pp $1-6$

17. Yin, C. : SAMCCO : a System of Contextual and Collaborative Mobile Learning in the Professional Situations (In French), Thesis of Ecole Centrale de Lyon, Computer Science Department, 25 January (2010). 
18. F. Soualah Alila, F. Mendes, C. Nicolle (2013). A Context-Based Adaptation In Mobile Learning. IEEE Computer Society Technical Committee on Learning Technology (TCLT), 2013, 15 (4), 5 p. <hal-00910239>

19. Gómez, S., Zervas, P., Sampson, D., \&Fabregat, R., (2014).Context-Aware Adaptive and Personalized Mobile Learning Delivery Supported by UoLmP".Journal of King Saud University - Computer and Information Sciences (2014) 26, 47-61 